\title{
A influência do dentifrício na abrasividade da estrutura dentinária: uma revisão
}

\section{narrativa}

The influence of toothpaste on the abrasivity of dental structure: a narrative review

\author{
La influencia de la pasta de dientes en la abrasividad de la estructura dentinaria: una revisión
} narrativa

\begin{abstract}
Resumo
A escovação dos dentes é considerada o método mais comum para manter uma boa higiene oral. No entanto, os dentifrícios demonstraram uma manifestação de desgaste dentário erosivo. Mesmo que um dentifrício não leve a nenhuma perda de superfície significativa, a estrutura do tecido duro pode tornar vulnerável à abrasão. O objetivo deste estudo foi analisar como os componentes das pastas dentais agem para o desgaste das estruturas dentárias. As bases de dados utilizadas foram PubMed e Scielo com as palavras chave: "dental abrasion", "toothpastes", "erosion". A busca se deu por artigos publicados de 2004 a 2021. A literatura revisada demonstrou que os dentifrícios com finalidade clareadora causam desgaste significativo da estrutura dental, devido aos altos níveis de abrasivos em sua composição, porém os dentifrícios convencionais também mostraram desgaste dentário em menor proporção. er Além disso, a hipersensibilidade dentinária tem sido considerada um problema decorrente da perda de estrutura dentária. Por isso, foi apresentado dentifrícios com efeito anti-erosivo com finalidade de prevenir a sensibilidade dentária. Cada dentifrício existente no mercado tem uma composição diferente dependendo do seu objetivo, e um nível abrasivo específico. Cabe ao Cirurgião-Dentista saber prescrever de forma correta o uso desses dentifrícios de acordo com a necessidade de cada paciente promovendo uma saúde bucal adequada.
\end{abstract}

Palavras-chave: Abrasão dental; Dentifrícios; Erosão.

\begin{abstract}
Tooth brushing is considered the most common method of maintaining good oral hygiene. However, dentifrices and dentifrices demonstrated a manifestation of erosive tooth wear. Even though a dentifrice does not lead to any significant surface loss, the hard tissue structure can make it vulnerable to abrasion. The aim of this study was to analyze how the components of toothpaste act for the wear of dental structures. The databases used were PubMed and Scielo with the keywords: "dental abrasion", "toothpastes", "erosion". The search was for articles published from
\end{abstract}


2004 to 2021. The literature reviewed showed that toothpastes with whitening purposes cause significant wear of the tooth structure, due to the high levels of abrasives in their composition, but conventional toothpastes also showed tooth wear in a lower proportion. In addition, dentin hypersensitivity has been considered a problem resulting from the loss of tooth structure. Therefore, toothpastes with anti-erosion effect were presented in order to prevent tooth sensitivity. Each toothpaste on the market has a different composition depending on its purpose, and a specific abrasive level. It is up to the Dental Surgeon to know how to correctly prescribe the use of these dentifrices according to the needs of each patient, promoting adequate oral health.

Keywords: Dental abrasion; Toothpastes; Erosion.

\section{Resumen}

El cepillado de los dientes se considera el método más común para mantener una buena higiene bucal. Sin embargo, los dentífricos demostraron una manifestación de desgaste dental erosivo. Aunque un dentífrico no da lugar a una pérdida significativa de superficie, la estructura del tejido duro puede hacerlo vulnerable a la abrasión. El objetivo de este estudio fue analizar cómo los componentes de la pasta de dientes actúan sobre el desgaste de las estructuras dentales. Las bases de datos utilizadas fueron PubMed y Scielo con las palabras clave: "dental abrasion", “toothpastes", "erosion". La búsqueda fue de artículos publicados entre 2004 y 2021. La literatura revisada mostró que los dentífricos con fines blanqueadores provocan un desgaste importante de la estructura dental, debido a los altos niveles de abrasivos en su composición, pero los dentífricos convencionales también presentan desgaste dental en menor medida. Además, la hipersensibilidad de la dentina se ha considerado un problema derivado de la pérdida de estructura dental. Por tanto, se presentaron dentífricos con efecto anti-erosión para prevenir la sensibilidad dental. Cada pasta de dientes del mercado tiene una composición diferente según su finalidad y un nivel de abrasivo específico. Corresponde al Cirujano Dentista saber prescribir correctamente el uso de estos dentífricos según las necesidades de cada paciente, promoviendo una adecuada salud bucal.

Palabras clave: Abrasión dental; Pastas de dientes; Erosión.

\section{Introdução}

Os dentifrícios desempenham um papel muito importante na transportação de agentes para a prevenção de doenças bucais. Defeitos erosivos são ocorrências de superfícies localizadas em partes mais expostas dos dentes por agentes químicos e impactos físicos, e isso leva a uma superfície de esmalte parcialmente desmineralizada, sendo sujeita a lesões abrasivas (Ganss, et al., 2016; Assunção et al., 2019).

Os dentifrícios possuem um nível de abrasividade em sua composição no qual é medido pela Abrasão Relativa de Dentina (RDA), que normalmente varia entre 50 e 250, então, quanto menor o nível de RDA menos abrasivo é, causando menor dano ao esmalte dentário. A fração particulada (principalmente Sílica) em uma formulação de dentifrício é um fator importante na sua eficácia, tendo formas, tamanhos e propriedades diferentes, a fim de alcançar características desejadas de um produto dependendo da sua indicação, como a limpeza e polimento da superfície dentária (Walsh et al.,2019).

Outro componente importante na composição dos dentifrícios é o flúor, pois quando comparado a dentifrícios não fluoretados, ele tem melhor efeito preventivo contra o desgaste dentário erosivo, e protege em diferentes graus, dependendo da concentração, sendo o ideal 1450 ppm para pacientes adultos e 1100 ppm para pacientes pediátricos (Walsh et al., 2019).

As biocorrosões dentárias podem ser definidas como a diminuição da superfície dentária, por agentes químicos e ácidos, mesmo que não haja interação com bactérias. O desgaste erosivo é definido como uma perda progressiva de estrutura dentária, porém difere da cárie pois, é uma perda irreversível de tecido dentário por meio de processos químicos não bacterianos, podendo ser tanto de origem intrínseca quanto extrínseca. (Branco et al., 2008; Magalhães, Wiegand, \& Buzalaf 2014; Nassar et al., 2018)

O objetivo do presente trabalho é revisar na literatura como os componentes dos dentifrícios agem para o desgaste das estruturas dentárias.

\section{Metodologia}

Para este trabalho, utilizou-se a pesquisa qualitativa de cunho descritivo com fonte secundária (Estrela, 2018). As 
bases de dados de pesquisa foram PubMed e Scielo. Foi realizada a busca através das palavras-chave: abrasividade, pastas dentais, erosão. A busca se deu por artigos publicados dos anos de 2004 a 2021.

\section{A Influência da Pasta Dental na Abrasividade da Estrutura Dentinária \\ 3.1 RDA e REA: conceito}

Existem alguns métodos descritos na literatura que tem como objetivo saber a real abrasividade que os dentifrícios possuem, estes métodos podem mensurar a Abrasividade Relativa do Esmalte (REA) e da Dentina (RDA), sendo o da dentina o mais utilizado, por sua eficácia. Ele consiste em medir o nível de abrasividade relativa das pastas dentais e de outros abrasivos. É de suma importância mensurar estes níveis, pois assim, pode-se avaliar a qualidade do dentifrício e produzir novas formulações podendo obter melhores resultados. Mesmo sendo o método mais utilizado, não deve ser o único, pois as causas para o desgaste abrasivo dentinário são multifatoriais (Cabezas et al.,2013). A International Standards Organization (ISO, 1995) afirma que o valor de RDA para dentina não pode passar de 250. Já para o esmalte, a ISO não definiu um valor máximo de REA (Joiner et al., 2004).

\subsection{A abrasividade dos dentifrícios e seus malefícios}

Os abrasivos são um dos ingredientes mais comuns dos dentifrícios e tem uma grande contribuição para a limpeza da superfície dentária. Temos diversos tipos de abrasivos encontrados nos dentifrícios como: sílica hidratada, carbonato de cálcio, metafosfato de sódio, fosfato dicálcico di-hidratado, alumina, bicarbonato de sódio, pirofosfato de cálcio, perlite e nanohidroxiapatita. Desses, os mais utilizados são a sílica hidratada e o carbonato de cálcio, e são normalmente utilizados em concentrações de 8 e 20\%. Vaz et al., 2018 mostra que fazer o uso diário desses abrasivos pode levar a uma modificação na superfície do esmalte, fazendo com que se diminua a adesão dos biofilmes e dos cromóforos, reduzindo assim a pigmentação. Já o bicarbonato de sódio pode ser usado em concentrações de 50\% por ser menos abrasivo, mas ele age de forma negativa com relação a formação de espuma durante a escovação. A quantidade de abrasivo a ser usado na formulação do dentifrício, depende também do resultado que se deseja alcançar (Lippert 2013; Nassar et al.,2018; Vaz et al., 2019).

Há no mercado alguns dentifrícios específicos para a sensibilidade, e esses são divididas em dois grupos, diferenciando o mecanismo de ação de cada uma. O primeiro grupo é composto por dentifrícios que bloqueiam as respostas dos nervos da polpa, causando um efeito anestésico, enquanto o segundo grupo compreende dentifrícios que fecham os túbulos dentinários fazendo que assim diminua a sensibilidade do dente. No geral os dentifrícios dessensibilizantes possuem ingredientes diferentes, assim como efeitos diferentes sobre a capacidade de fechar os túbulos dentinários. Todos esses dentifrícios são bem parecidos, pois possuem níveis de abrasividade dentro de um valor de RDA que vai variar entre 20 e 120 . Em estudos recentes, obtiveram resultados deque dentifrícios com altos valores de RDA fizeram ter mais perda de dentina após a escovação. A abrasividade dos dentifrícios dessensibilizantes pode ter um efeito adverso sobre a oclusão dos túbulos dentinários porque os túbulos podem ser reabertos durante a escovação já que pode haver um valor de RDA relativamente alto, e consequentemente a abrasividade e recidiva da sensibilidade do dente (Arnold et al., 2016; João-Souza et al., 2019).

A cárie dentária pode ter impacto direto em relação a abrasividade pela pasta dental, pois a cárie inicial é caracterizada por uma desmineralização localizada em forma de mancha branca. Essas lesões não requerem intervenção restauradora se retirada o fator causal, e tratadas para a remineralização da superfície. Os compostos existentes nos dentifrícios tais como o flúor, e abrasivos, são necessários para remoção de manchas, limpeza adequada, remineralização, no entanto, como as lesões de cárie tem uma superfície comprometida comparada ao esmalte sólido, fica assim, sendo mais sujeito a abrasão por escovação dental (Nassar et al., 2018).

Os ácidos intrínsecos e extrínsecos, interagem diretamente com as superfícies lisas dos dentes e quando o líquido 
ácido envolve a superfície dental, ocorre uma agressão direta aos minerais do dente, podendo ocorrer desmineralização erosiva. Quando há exposição contínua aos ácidos, pode se desenvolver lesões clinicamente visíveis e quando isso acontece, o brilho natural do esmalte desaparece, seguido pelo desenvolvimento de lesões. É importante pontuar que a dentina é geralmente exposta em estágios iniciais, por exemplo, na região cervical, que é área onde a cobertura de esmalte é relativamente fina. Portanto, não apenas o esmalte, mas também a dentina, são tecidos importantes para estratégias que visam prevenir a progressão da biocorrosão dental, levando em consideração os efeitos dos dentifrícios (Ganss, Schulze, \& Schlueter 2013).

Esses ácidos, conseguem dissolver os minerais que se encontram na superfície dos dentes, deixando uma camada superficial desmineralizada e amolecida, que pode ser removida com a escovação, se essa dissolução e remoção se repetir várias vezes, pode ocasionar uma perda permanente de tecidos duros do dente. Esses ácidos podem ser fornecidos de diferentes formas, intrínseca ou extrínseca, sendo os intrínsecos vindos do suco gástrico que contem ácido clorídrico, que entram em contato com a superfície dentária através do vômito ou o refluxo gástrico. Já os extrínsecos são fornecidos principalmente com os alimentos consumidos no dia a dia, medicamentos e outros (Magalhães, Wiegand, \& Buzalaf 2014; Nassar et al., 2018).

As abrasões dentárias podem ser definidas como a perda de superfície de esmalte sem lesão cariosa. São diversos fatores que podem ocasionar a abrasão dentária. Dentre eles, encontramos os hábitos de escovação, frequência e força na escovação, sendo assim é sempre importante que o profissional alerte seus pacientes sobre as consequências, ensinando a forma correta de higienizar a cavidade bucal, e também a abrasividade contida nos dentifrícios. Além disso, temos também a relação com o comprimento, rigidez e o formato das cerdas das escovas de dente. Tudo isso pode resultar em hipersensibilidade dentinária, superfícies dentárias expostas, e em longo prazo, pode haver perda de dimensão vertical, má oclusão e problemas estéticos. Pode-se atingir uma remineralização e um endurecimento da superfície dentária caso aumente a frequência de escovação corretamente (Hilgenberg et al.,2011; Nassar et al., 2018; Vaz et al., 2019).

\subsection{Composição dos dentifrícios}

Para compreensão dos efeitos que os dentifrícios têm nos tecidos duros dentais requer um entendimento do mecanismo patológico da condição, suas características histológicas e propriedades físicas. A biocorrosão dental é causada pela exposição das superfícies dentais tanto por ácidos extrínsecos quanto por ácidos intrínsecos e esses não são relacionados ao metabolismo bacteriano (Ganss, Schulze, \& Schlueter, 2013).

A desmineralização erosiva na dentina é um processo centrípeto, porque enquanto os minerais do tecido estão se dissolvendo, a parte orgânica não é degradada, em vez disso, o colágeno desmineralizado continua na superfície, formando uma maior espessura, sendo resistente à impactos físicos e podendo ser degradado por colagenases (Schlueter et al., 2012).

Nos dentifrícios o ingrediente ativo que é mais comumente encontrado é o flúor. Também há outros ingredientes compostos de fluoreto sendo usados, como fluoreto de sódio (NaF), monofluoreto de fosfato de sódio (MFP), fluoreto estanhoso (SnF 2) e fluoreto de amina (AmF). As concentrações de flúor nos dentifrícios vão variar entre 550 a 1450 ppm. Há estudos que mostraram que SnF 2 teve efeito protetor superior do que produtos contendo $\mathrm{NaF}$, que teve poucos efeitos de proteção. A explicação simples sobre isso, é que a ação física das partículas abrasivas na fase sólida ou líquida, atrapalha o adiantamento dos sais de $\mathrm{Sn}$ ou remove as estruturas superficiais do esmalte que estão enriquecidas com Sn. Essa é a descoberta de que um SnF 2 em gel com uma concentração de Sn semelhante aos dentifrícios (sem abrasivos) forneceram grande proteção, mesmo com erosões severas, e com ou sem escovação. (Ganss, Schulze, \& Schlueter 2013; Magalhães, Wiegand, \& Buzalaf 2014).

Compostos inorgânicos diferentes do flúor ou íons estanhosos foram introduzidos em dentifrícios alegando ter propriedades de prevenção contra erosão e abrasão. A hidroxiapatita (HA) na forma nanocristalina foi usado em formulações com e sem flúor. O Nano-HA tem sido estudado e até então, não há comprovação de que o HA em sua forma nano-cristalina 
atua de maneira diferente nos tecidos duros dentais. $\mathrm{O}$ nano-HA tem menor eficácia do que o $\mathrm{NaF}$ em um modelo de cárie com ciclagem de pH e não tem efeito biocorrosivo e quando combinado com o flúor, o nano-HA pode diminuir o flúor disponível no dentifrício (Ganss, Schulze, \& Schlueter, 2013). Além dos compostos inorgânicos, as substâncias orgânicas têm sido estudadas. Acredita-se que polímeros como mucina ou carboximetilcelulose podem formar camadas que protegem e/ou fortaleçam a superfície dental (Pepla et al.,2014; Scaramucci et al., 2011).

Foi encontrado que os dentifrícios com fluoreto de sódio com o mesmo teor de flúor variaram de acordo com as suas propriedades inibidoras da biocorrosão, e essas substâncias tais como, carboximetilcelulose, alginato, goma xantana, ou compostos de polietilenoglicol possa ser um fator que explique essa variação nos efeitos. Os efeitos da abrasividade dos dentifrícios nos tecidos saudáveis têm sido estudados com frequência. No esmalte sólido, o efeito abrasivo dos dentifrícios tende a ser reduzido, mas em condições erosivas de ciclagem de $\mathrm{pH}$, a escovação pode aumentar a perda de substância de forma distinta. Alguns estudos mostraram que os dentifrícios com flúor tendem a oferecer uma certa proteção, porém lesões erosivas podem se desenvolver apesar do uso de dentifrícios com flúor. (Ganns, Schulze, \& Schlueter, 2013; Martins et al., 2020; Tenuta \& Cury 2010).

\subsection{Dentifrícios clareadores}

Dentifrícios clareadores têm sido muito usadas na odontologia estética para clarear dentes por serem de baixo custo e por serem de fácil aplicação. Em um estudo, autores mostraram que há dentifrícios clareadores que possuem benefícios efetivos na descoloração externa da superfície do dental (Vaz et al., 2019).

O mecanismo de clareamento dos dentifrícios depende da presença dos princípios ativos, como as proteases, que vão ajudar a reduzir a película manchada; agentes oxidantes (peróxido de hidrogênio e cloreto de sódio) que possuem a capacidade de penetrar nos dentes e ajudar a limpar as manchas externas; e os compostos à base de fosfato, como por exemplo o pirofosfato, o tripolifosfato e o hexametafosfato, que desloca macromoléculas carregadas negativamente que estão associadas à película de esmalte adquirida (Vaz et al., 2019; Shamel, Al-Ankily, \& Bakr, 2019).

Além de todos esses componentes, ainda existem os agentes ópticos, como o covarine azul, um pigmento que iguala às propriedades do esmalte quanto aos comprimentos de onda de espalhamento na extensão do azul, alterando do amarelo para o azul. Enfim, os dentifrícios clareadores também contêm mais agentes abrasivos do que os dentifrícios convencionais, intensificando a remoção mecânica da placa dental e o controle de manchas externas. Alguns estudos mostraram que dentifrícios contendo covarine azul foi o único testado que houve diminuição significativa da cor amarelo e aumento da cor azul resultando na melhora do branqueamento dental. Essa diminuição do valor amarelo se deve à deposição dos pigmentos na superfície do esmalte, o que modifica nos caracteres óticos da superfície do dente (Shamel, Al-Ankily, \& Bakr, 2019; Vaz et al., 2019).

Grande parte dos estudos sobre o potencial de abrasão dos dentifrícios clareadores foi feita em esmalte, uma vez que o produto é indicado para ser aplicado na coroa dos dentes. No entanto, alguns pacientes poderão ter exposição de raiz devido a doenças periodontais ou abrasão pela escovação dentária, expondo a dentina aos ácidos dietéticos e também à ação da escovação. Levando em consideração que os dentifrícios clareadores têm mostrado efeitos prejudiciais no esmalte erodido, supondo que efeitos semelhantes acontecerão em dentina erodida. Esses resultados também estão de acordo com estudos anteriores realizados em dentina sadia. Diferente do esmalte, não tem suporte suficiente para que a escovação eleve o desgaste da dentina erodida. Alguns estudos demonstraram que a matriz dentinária orgânica desmineralizada resiste à abrasão quando usada muita força na escovação, enquanto outros estudos mostraram que o desgaste dentinário vai aumentando junto com a abrasividade dos dentifrícios (valor RDA). Outro estudo comparou a eficácia do componente abrasivo (perlita / carbonato de cálcio) e do componente enzimático (papaína e bromelaína) do dentifrício clareador na remoção de manchas e concluíram que 
dentifrícios clareadores com ação abrasiva e ação enzimática tem eficácia igual na remoção de manchas extrínsecas, portanto, o dentifrício clareador de ativo abrasivo deve ser usado com muita cautela (Patil et al., 2015; Vaz et al., 2019).

Amostras de dentifrício contendo fosfato dissódico apresentaram valores de desgaste intermediários (Oral-B 3D White). O tipo de sal de pirofosfato é o que pode explicar as diferenças entre os dentifrícios clareadores. Os sais de pirofosfato contendo tetra cátions podem ser mais prejudiciais do que aqueles que não o contém. A combinação de pirofosfato e partículas abrasivas é conhecida por ajudar no aumento da abrasividade de alguns dentifrícios clareadores. Os dentifrícios têm a função de potencializar a ação mecânica de limpeza da escovação dentária. Este agente de limpeza pode variar entre as formulações de diferentes dentifrícios; a eficiência na remoção de manchas e do polimento dentário pode ser alcançada em maior ou menor grau, dependendo do tipo, distribuição, tamanho e morfologia das partículas de abrasivo utilizado. Diversas formas físicas, como pasta, creme, gel e pó são os mais comercializados. (Santos et al., 2015; Vaz et al., 2018).

O cirurgião-dentista deve estar atento às composições dos dentifrícios para que possa prescrevê-los de forma adequada para os seus pacientes e auxiliá-los no uso correto de dentifrícios clareadores e de anticálculos, principalmente para aqueles pacientes que possuem raiz exposta. A exposição da raiz está envolvida na etiologia da hiperestesia, que pode ter um efeito negativo para a qualidade de vida dos pacientes (Vaz et al., 2019).

No mercado existem muitos dentifrícios "multifuncionais" ou "tudo-em-um" que afirmam serem clareadores efetivos. Eles normalmente contêm abrasivos especiais e/ ou agentes de branqueamento. Para dentifrícios clareadores, também distingue entre prevenção de manchas e remoção de manchas (ambos externos). Os abrasivos são os componentes mais importantes nas formulações de dentifrícios para uma remoção de manchas mais eficiente, e esses dentifrícios clareadores muitas das vezes (mas nem sempre) contêm abrasivos duros e uma maior quantidade dos mesmos abrasivos do que os dentifrícios convencionais, para atingir uma remoção eficiente para manchas externas (Epple, Meyer, \& Enax, 2019).

Assim, a abrasividade de um dentifrício é limitada por uma ação prejudicial ao esmalte, dentina exposta e gengiva, por componentes que são muito abrasivos. Um dentifrício com abrasividade muito baixa (por exemplo, para sensibilidade e limpeza da dentina exposta) pode levar ao aumento da coloração amarelada da superfície do dente devido a menor eficácia de limpeza da placa bacteriana (Epple, Meyer, \& Enax, 2019).

Abrasivos comuns são, sílica ( $\mathrm{SiO} 2 \cdot \mathrm{n} \mathrm{H} 2 \mathrm{O}$ ), carbonato de cálcio (CaCO3), e alumina (Al2O3). Esses abrasivos variam em tamanho da partícula, morfologia e dureza. As propriedades dos abrasivos de sílica dependem de vários parâmetros, como teor de água, forma e tamanho da partícula. A hidroxiapatita particulada é um agente biomimético usado em cuidados para prevenção de problemas bucais como a biocorrosão dental. Além disso, ela também se apresenta como um abrasivo promissor devido à sua semelhança com os minerais dentais, além de ser um clareador efetivo, e não é devido apenas ao polimento, mas também à sua presença na superfície do dente. Epple et al., (2019) demonstraram que as partículas de hidroxiapatita aderem melhor ao esmalte, porém, uma baixa concentração de hidroxiapatita leva a uma menor cobertura da superfície da estrutura dental. Um estudo mostrou que o monossilicida de cálcio (CaSi) é capaz de nuclear a hidroxiapatita, o que muda o equilíbrio para a remineralização e reduz a desmineralização do esmalte. Além disso, a própria hidroxiapatita nucleada pode atuar como um material de sacrifício para o esmalte durante a exposição subsequente ao ácido (Buzalaf et al., 2021; Epple, Meyer, \& Enax, 2019).

Um dentifrício contendo hidroxiapatita de carbonato de zinco pode levar à adsorção de partículas na superfície do dente. Fabritius-Vilpoux et al., (2019) estudaram quantitativamente a interação entre os dentes e a hidroxiapatita particulada in vitro e mostrou um desenvolvimento de abrasivos que removem manchas com um mínimo de danos no esmalte. Em um outro estudo foi demonstrado que o $\mathrm{CaSi}$ incorporado em um dentifrício pode formar Hidroxiapatita nas superfícies do esmalte in vitro e in situ, para prevenir a desmineralização do esmalte e promover a sua remineralização (Buzalaf et al., 2021; Epple, Meyer, \& Enax, 2019). 
Os dentifrícios com valores de RDA menor que 250 geralmente são aceitos como seguros, já um meio de avaliar a limpeza efetiva dos dentifrícios e abrasivos é o valor da taxa de limpeza da película (PCR), geralmente, um alto valor de RDA está acompanhado de um alto valor de PCR, pois ambos são baseados no mesmo efeito (abrasão mecânica na superfície dental). (Buzalaf et al., 2021; Epple, Meyer, \& Enax, 2019).

\subsection{Pasta anti-erosiva}

O uso de dentifrícios fluoretados convencionais mostrou ter uma menor eficácia na prevenção do desgaste dentário erosivo para fluoreto altamente concentrado e aplicado com frequência. Contudo, comparando dentifrícios experimentais e os que contém compostos, como, tetro fluoreto de titânio ou estanhoso mostraram maior eficácia. Nos últimos anos, foram comercializados vários dentifrícios com "reparadores", e " anti-erosivo "contendo outros componentes ativos além de fluoretos, por exemplo, nanopartículas de hidroxiapatita, nanopartículas de zinco-carbonato-hidroxiapatita, nitrato de potássio, sais estanhosos, quitosana e/ou proteínas (Hara, Lippert, \& Zero, 2013; Yetkiner, Attin, \& Wiegand, 2014).

É possível que a escovação impeça ou remova os fatores essenciais para efeito anti-erosivo. Até agora, a maioria dos estudos testou um efeito protetor dos dentifrícios com fórmulas especiais, contra a biocorrosão, principalmente em amostras de esmalte. Considerando que a dentina é exposta pela biocorrosão com frequência em pacientes de alto risco, por exemplo, que sofrem de distúrbios alimentares, refluxo, ou abuso de álcool, a prevenção da biocorrosão da dentina por meio de produtos de higiene bucal está se tornando cada vez mais essencial a rotina de cada indivíduo. A maioria dos dentifrícios anti-erosivos ou reparadores reduziram significativamente a perda de dentina, mas não foram melhores que os dentifrícios convencionais. No estudo realizado por Yetkiner, Attin e Wiegand (2014), o efeito protetor contra a erosão dos dentifrícios, foi analisado sob um alto pH ácido (ácido clorídrico) geralmente presente no estômago (Yetkiner, Attin, \& Wiegand, 2014).

É importante ressaltar que o dentifrício sem fluoreto contendo quitosana reduziu a biocorrosão da dentina entre 40 a $60 \%$, apesar do valor do RDA ser muito alto. Os dentifrícios contendo quitosana já se mostraram bastante eficazes na redução da biocorrosão do esmalte. A quitosana é um polissacarídeo catiônico, que se apresenta em multicamadas resistentes a ácidos. Os seus efeitos lubrificantes desempenham um papel importante, pois se for adicionada àos dentifrícios, reduz o efeito abrasivo dessas partículas. Portanto, a quitosana pode aumentar o efeito dos dentifrícios contendo fluoreto estanhoso, que mostraram um efeito anti-erosivo positivo (Ganss et al.,2011; Yetkiner, Attin, \& Wiegand, 2014).

No caso da dentina erodida, quando a matriz orgânica não é removida totalmente, o estanho é ligado ao colágeno e assim, leva a um aumento da resistência aos ácidos comparando ao fluoreto de sódio. Isso também foi confirmado parcialmente no estudo de Yetkiner, Attin, e Wiegand (2014), uma vez que o dentifrício contendo fluoreto estanoso e quitosana apresentou um potencial protetor rapidamente melhor do que o dentifrício contendo fluoreto de amina em condições erosivas extrínsecas. O produto livre de fluoreto contendo nanopartículas de hidroxiapatita de carbonato de zinco (Biorepair) foi menos eficaz (Ganss et al., 2011; Yetkiner, Attin, \& Wiegand, 2014).

\section{Discussão}

A abrasividade dos dentifrícios vai depender de diversos fatores, dentre eles o principal é o teor de abrasivos. Alguns outros ingredientes como $\mathrm{CaCO} 3$, hidroxiapatita e outras nanopartículas também contribuem para seu nível de abrasividade. Todos os dentifrícios possuem uma grande variedade na formulação, tendo ingredientes diferentes, podendo dizer que seja quase impossível determinar a influência de uma substância específica em sua abrasividade (Arnold et al., 2016). Com isto, existem diversas composições de diferentes dentifrícios, é fato que os testes desses dentifrícios com abrasivos específicos seja o ideal, porém, é concordante que mesmo assim é muito difícil descobrir qual componente tem maior influência na abrasividade da estrutura dental, já que existem outros fatores que também contribuem para esse desgaste erosivo. 
Outro fator importante que se deve levar em consideração é a sensibilidade causada por esses abrasivos que contêm nos dentifrícios. Tem aumentado muito a prevalência de hipersensibilidade dentinária nos últimos anos e as causas vem sendo os túbulos dentinários que estão abertos devido as recessões gengivais e consequentemente a biocorrosão da dentina cervical. Essa erosão pode ocorrer por diversos motivos, dos quais podem ser, as bebidas erosivas, o refluxo, transtornos alimentares e também o uso de dentrifrícios e escovas de dentes (Ganss, Schulze, \& Schlueter, 2013). Há algumas opções para tentar diminuir essa hipersensibilidade, por exemplo fazendo-se o uso de dentifrícios que tenham em sua composição agentes dessensibilizantes. Os dentifrícios associados com alimentação, problemas fisiológicos e com a própria escova dental, tem maiores impactos na causa da abrasividade da estrutura dental, e assim resultando na hipersensibilidade dental, causando desconforto ao paciente. Pode-se concordar que o ideal é o uso de dentifrícios com agentes dessensibilizantes. É interessante também que o paciente evite alimentos ácidos que provoque a progressão da lesão abrasiva.

Clinicamente, lesões erosivas graves parecem duras quando arranhadas com uma sonda, o que indica que a histologia in vivo dessas lesões pode ser diferente da erosão experimental. A matéria orgânica encontrada na superfície pode ter efeitos na progressão da biocorrosão dental, impactos de escovação ou na ação dos componentes ativos, portanto, existem alguns estudos de que os dentifrícios com flúor oferecem maior proteção contra a biocorrosão e ajuda na prevenção da gengivite (Ganss, Schulze, \& Schlueter, 2013). Como existem diversas variáveis que influenciam nas lesões abrasivas, realmente pode haver uma diferença clínica na lesão de uma pessoa e uma lesão do experimento feito. Por isso é mais complexo o fato de descobrir se um componente em específico é, de fato, o fator causador da lesão abrasiva.

Os dentifrícios têm formulações complexas e a ação durante a biocorrosão dental ainda não é compreendida. Na prevenção da cárie, os ingredientes que são ativos vão atuar em um ambiente que é parcialmente protegido contra os impactos físicos, e os abrasivos aumentam os benefícios dos dentifrícios pois possuem propriedades de limpeza. Na biocorrosão , que é algo que acomete as superfícies lisas, sem placas e áreas oclusais, os ingredientes ativos específicos vão oferecer uma proteção, mas o componente abrasivo é um fator de contra-ataque, e a junção de ambos não é totalmente explicado (Ganss, Schulze, \& Schlueter, 2013). Mesmo que os agentes de limpeza tenham um nível abrasivo prejudicial, também tem ação protetora, já que nas áreas que a escova dental não alcança, os agentes de limpeza fazem o trabalho de limpar a área com placa bacteriana, o que se torna um benefício contra a doença cárie.

A diferença de maior potencial de abrasividade entre os dentifrícios é devido à sua complexa composição. Vários fatores podem intervir na abrasividade do dentifrício, como por exemplo, o tipo de abrasivo, o tamanho do abrasivo, a quantidade de abrasivo e presença de alguns compostos ativos. Devido à grande variação dos dentifrícios, é muito difícil definir o dentifrício padrão adequado, que é representado por todas os dentifrícios (Vaz et al., 2019). Como já se sabe, os abrasivos também têm seus níveis, sendo prejudiciais, no entantto eficientes, cumprindo seu papel de limpeza. Por isso, é interessante considerar que fatores que vão influenciar no potencial abrasivo.

Um estudo mostrou uma deficiência na correlação entre os valores de RA (abrasão relativa), perda de volume e RDA, e também na comparação dos valores para as pastas de polimento RDA 170 e RDA 250. Após 1 e 6 h de escovação, o RDA 170 teve uma produção de maiores valores de RA e perdeu mais volume do que o RDA 250. Isso também está de acordo com os resultados obtidos anteriormente por Johannsen et al., (2013), destacam importância de se levar em consideração um valor qualitativo (rugosidade) e um valor quantitativo (perda de volume) ao fazer a descrição da abrasividade de um dentifrício. Há estudos que indicam que um dentifrício clareador não causa maior desgaste do que um dentifrício convencional, mas há também outros estudos que dizem que o maior desgaste foi causado pelos dentifrícios s clareadores em comparação com os dentifrícios convencionais. Foi descoberto que o esmalte amolecido apresentava um aumento na abrasão, Kielbasa et al., (2005). No estudo de Johannsen et al., (2013) comparou-se a escovação com água, pastas de detergente e dentifrícios e foi descoberto que a escovação apenas com detergentes também causava perda de dentina (Johannsen et al., 2013). Vários estudos 
feitos dizem que os dentifrícios clareadores são mais prejudiciais do que as convencionais, e outros que dizem o contrário (Demarco, Meireles, \& Masotti, 2009; Epple, Meyer, \& Enax, 2019; Kalliath et al., 2018; Vaz et al., 2019). De fato, há vários estudos sobre esse assunto, e muitos autores que divergem opiniões, mas é interessante pensar que em todos esses estudos feitos existiram inúmeras variáveis, como tipo de escovação, tipo de cerdas, força de escovação, entre outras. Então esses fatores podem influenciar no resultado final comparativo entre dentifrícios pastas convencionais e dentifrícios clareadoras.

\section{Conclusão}

Cada dentifrício existente no mercado tem uma composição diferente dependendo do seu objetivo e um nível abrasivo específico. Os dentifrícios com altos valores de RDA resultaram em uma perda maior de dentina após a escovação.

Quanto a composição, o flúor é um dos principais componentes ativos encontrado nos dentifrícios no geral, e a partir deste trabalho entende-se que o flúor tem um alto nível protetor da estrutura dental contra o efeito abrasivo dos dentifrícios. A quitosana apresentou-se bastante eficaz na prevenção da biocorrosão, pois reduz a abrasão das partículas, e também aumenta o efeito dos dentifrícios contendo fluoreto estanhoso, que mostrou ser um ótimo anti-erosivo. A hidroxiapatita é um composto que tem função preventiva, pois remove manchas com o mínimo de danos ao esmalte e previne a desmineralização, promovendo a remineralização.

Os dentifrícios clareadores mostraram ter um efeito semelhante aos convencionais pois remove as manchas superficiais, mas não clareia de fato. Todavia, o cirurgião-dentista deve estar sempre atento aos compostos de cada dentifrício para poder prescrevê-lo da forma correta a cada paciente e ensinar a técnica correta de escovação, promovendo qualidade de saúde bucal.

\section{Referências}

Arnold, W. H., Gröger, C. h., Bizhang, M., \& Naumova, E. A. (2016). Dentin abrasivity of various desensitizing toothpastes. Head \& face medicine, 2;12-16.

Assunção, C. M., Lussi, A., Rodrigues, J. A., \& Carvalho, T. S. (2019). Efficacy of toothpastes in the prevention of erosive tooth wear in permanent and deciduous teeth. Clinical oral investigations, 23(1), 273-284.

Branco, C. A., Valdivia, A. D. C. M., Soares, P. B. F., Fonseca, R. B., Fernandes Neto, A. J., Soares, C.J. (2008) Dental erosion: diagnosis and treatment options. Rev. Odontol. UNESP. 37(3), 235-242

Buzalaf, M., Levy, F. M., Gomes, B., Valle, A. D., Trevizol, J. S., Magalhães, A. C., \& Joiner, A. (2021). Protective effect of calcium silicate toothpaste on enamel erosion and abrasion in vitro. Heliyon, 7(4).

Cabezas, G. C., Hara, A. T., Hefferren, J., \& Lippert, F. (2013). Abrasivity testing of dentifrices - challenges and current state of the art. Monographs in oral science, 23, 100-107.

Demarco, F. F., Meireles, S. S., \& Masotti, A. S. (2009). Over-the-counter whitening agents: a concise review. Brazilian Oral Research. 23:64-70.

Epple, M., Meyer, F., \& Enax, J. (2019). A Critical Review of Modern Concepts for Teeth Whitening. Dentistry journal, 7(3), 79.

Estrela, C. (2018). Metodologia Científica: Ciência, ensino, pesquisaa. Artes Médicas, (3)

Fabritius-Vilpoux, K., Enax, J., Herbig, M., Raabe, D., \& Helge-Otto, F. (2019). Bioinspired, Biomimetic and Nanobiomaterials. 8(2), 141-53

Ganss, C., Lussi, A., Grunau, O., Klimek, J., \& Schlueter, N. (2011). Conventional and anti-erosion fluoride toothpastes: effect on enamel erosion and erosionabrasion. Caries research, 45(6), 581-589.

Ganss, C., Marten, J., Hara, A. T., \& Schlueter, N. (2016). Toothpastes and enamel erosion/abrasion - Impact of active ingredients and the particulate fraction. Journal of dentistry, 54, 62-67.

Ganss, C., Schulze, K., \& Schlueter, N. (2013). Toothpaste and erosion. Monographs in oral science, 23, 88-99.

Hara, A. T., Lippert, F., \& Zero, D. T. (2013). Interplay between experimental dental pellicles and stannous-containing toothpaste on dental erosion-abrasion. Caries research, 47(4), 325-329.

Hilgenberg, S. P., Pinto, S. C. S., Farago, P. V., Santos, F. A., \& Wambier, D. S. (2011) Physical-chemical characteristics of whitening toothpaste and evaluation of its effects on enamel roughness. Brazilian oral research, 25(4), 288-294. 
João-Souza, S. H., Scaramucci, T., Bühler Borges, A., Lussi, A., Saads Carvalho, T., \& Corrêa Aranha, A. C. (2019). Influence of desensitizing and antierosive toothpastes on dentine permeability: An in vitro study. Journal of dentistry, 89, 103176.

Johannsen, G., Tellefsen, G., Johannsen, A., \& Liljeborg, A. (2013). The importance of measuring toothpaste abrasivity in both a quantitative and qualitative way. Acta odontologica Scandinavica, 71(3-4), 508-517.

Joiner, A., Pickles, M. J., Tanner, C., Weader, E., \& Doyle, P. (2004). An in situ model to study the toothpaste abrasion of enamel. Journal of clinical periodontology, 31(6), 434-438.

Kalliath, C., Mukunda, A., Pynadath, M., Venugopal, V., \& Prethweeraj, J. (2018). Comparison between the effect of commercially available chemical teeth whitening paste and teeth whitening paste containing ingredients of herbal origin on human enamel. Ayu, 39(2), 113-117.

Kielbassa, A. M., Gillmann, L., Zantner, C., Meyer-Lueckel, H., Hellwig, E., \& Schulte-Mönting, J. (2005). Profilometric and microradiographic studies on the effects of toothpaste and acidic gel abrasivity on sound and demineralized bovine dental enamel. Caries research, 39(5), 380-386.

Lippert F. (2013). An introduction to toothpaste - its purpose, history and ingredients. Monographs in oral science, 23, 1-14.

Magalhaes, A. C., Wiegand, A., \& Buzalaf, M. A. (2014). Use of dentifrices to prevent erosive tooth wear: harmful or helpful? Brazilian oral research, 28 Spec No, 1-6.

Martins, C. C., Firmino, R. T., Riva, J. J., Ge, L., Carrasco-Labra, A., Brignardello-Petersen, R., Colunga-Lozano, L. E., Granville-Garcia, A. F., Costa, F. O., Yepes-Nuñez, J. J., Zhang, Y., \& Schünemann, H. J. (2020). Desensitizing Toothpastes for Dentin Hypersensitivity: A Network Meta-analysis. Journal of dental research, 99(5), 514-522.

Nassar, H. M., Lippert, F., Eckert, G. J., \& Hara, A. T. (2018). Impact of toothbrushing frequency and toothpaste fluoride/abrasivity levels on incipient artificial caries lesion abrasion. Journal of dentistry, 76, 89-92.

Patil, P. A., Ankola, A. V., Hebbal, M. I., \& Patil, A. C. (2015). Comparison of effectiveness of abrasive and enzymatic action of whitening toothpastes in removal of extrinsic stains - a clinical trial. International journal of dental hygiene, 13(1), 25-29.

Pepla, E., Besharat, L. K., Palaia, G., Tenore, G., \& Migliau, G. (2014). Nano-hydroxyapatite and its applications in preventive, restorative and regenerative dentistry: a review of literature. Annali di stomatologia, 5(3), 108-114.

Santos, L.B., Rios, A.C.F., Oliveira, V.M.B., Lopes, S.C.F.L., \& Dantas, T.S. (2015) Abrasivos: uma análise de dentifrícios comercializados em Salvador. Revista Bahiana de Odontologia. 5(3),141-52.

Scaramucci, T., Hara, A. T., Zero, D. T., Ferreira, S. S., Aoki, I. V., \& Sobral, M. A. (2011). In vitro evaluation of the erosive potential of orange juice modified by food additives in enamel and dentine. Journal of dentistry, 39(12), 841-848.

Schlueter, N., Glatzki, J., Klimek, J., \& Ganss, C. (2012). Erosive-abrasive tissue loss in dentine under simulated bulimic conditions. Archives of oral biology, 57(9), 1176-1182.

Shamel, M., Al-Ankily, M. M., \& Bakr, M. M. (2019). Influence of different types of whitening tooth pastes on the tooth color, enamel surface roughness and enamel morphology of human teeth. F1000Research, 8, 1764.

Tenuta, L. M., \& Cury, J. A. (2010). Fluoride: its role in dentistry. Brazilian oral research, 24 Suppl 1, 9-17.

Vaz, V. T. P., Jubilato, D. P., Oliveira, M. R. M., Bortolatto, J. F., Floros, M. C., Dantas, A. A. R., \& Oliveira Junior, O. B. (2019) Whitening toothpaste containing activated charcoal, blue covarine, hydrogen peroxide or microbeads: which one is the most effective? J Appl Oral Sci. 14-27

Walsh, T., Worthington, H. V., Glenny, A. M., Marinho, V. C., \& Jeroncic, A. (2019). Fluoride toothpastes of different concentrations for preventing dental caries. The Cochrane database of systematic reviews, 4;3(3).

Yetkiner, A. A., Attin, T., \& Wiegand, A. (2014). Prevention of dentine erosion by brushing with anti-erosive toothpastes. Journal of dentistry, 42(7), 856861. 